\title{
Behavior of the U.S. Economic Growth: An Empirical Analysis
}

\author{
Md Niaz Murshed Chowdhury ${ }^{1}$, Sharmina Khanom ${ }^{2}$, Mahamuda Firoj ${ }^{2}$, Shamima Nasrin Emu ${ }^{2}$ \\ ${ }^{1}$ Department of Economics, University of Nevada Reno, Reno, USA \\ ${ }^{2}$ Department of Economics and Banking, International Islamic University Chittagong, Chittagong, Bangladesh
}

Email address:

niaz060707@gmail.com (Md N. M. Chowdhury)

\section{To cite this article:}

Md Niaz Murshed Chowdhury, Sharmina Khanom, Mahamuda Firoj, Shamima Nasrin Emu. Behavior of the U.S. Economic Growth: An Empirical Analysis. International Journal of Finance and Banking Research. Vol. 4, No. 2, 2018, pp. 25-39.

doi: $10.11648 /$ j.jifbr.20180402.11

Received: January 20, 2018; Accepted: May 22, 2018; Published: July 3, 2018

\begin{abstract}
The purpose of this paper is to measure behavior of the U.S. economic growth and views the future from 20152035 while pretending that the financial crisis did not happen. The sample period for investigation in 1945-2015 the empirical analysis of this study employed annual secondary time series data, collected from different sources. Three influential factors of growth are the labor force, technology, and capital, and our most important finding is that growth of technology is the highest influential among them and thus special attention should be given its advancement. The growth rate of GDP is at $2.07 \%$ as of 2015 , but using the first order exponential model, it will slow down to $1.38 \%$ by 2035 . The findings were conclusive in that total production was made up of 57.5\% technology, $28.8 \%$ labor, and $12.8 \%$ capital. Technology makes up the greatest fraction of total production and changes in labor and capital would not affect the growth rate as much as technology can and it was projected that in 20 years, the GDP level could be anywhere from $\$ 19,138.8$ using the polynomial model to $\$ 34,681.8$ using the first order exponential model. The longest business cycle the U.S. has experienced was from 1989-2008, under which the economy had its longest stretch of better than experience performance. Growth gradually accelerated after 1950, reached a peak in the middle of the 20th century, and has been slowing down since. The most effective way to increase the growth rate is to increase the level of technology because the diminishing returns to labor and capital decrease the growth rate of GDP. A key idea to take away from this paper is that while a model fit the current data well, it may weigh recent events to heavily, recessionary or exponential growth, the average between the most optimistic and pessimistic models may be the best bet.
\end{abstract}

Keywords: Economic Growth, Technology, Polynomial Model, Productivity, Exponential Model, Linear Model

\section{Introduction}

The U.S Economy has been going through many ups and downs in recent history and the economy was very sluggish during recession period. The continued strength and vitality of the U.S. economy continue to astonish economic forecasters. In this view, technology is profoundly altering the nature of business, leading to permanently higher productivity growth throughout the economy. Skeptics remain, however, arguing that the recent success reflects a series of favorable, but temporary, shocks. This argument is buttressed by the view that the U.S. economy. Productivity growth, capital accumulation, and the impact of technology were topics once reserved for academic debates, but the recent success of the U.S. economy has moved them into popular discussion. That intangibles, and more generally, knowledge capital should be such an important driver of modern economic growth is hardly surprising, given the evidence from everyday life and the results of basic intertemporal economic theory.

The acceleration of average labor productivity (ALP) growth in the. 1990s. After a twenty-year slowdown dating from the early 1970s, ALP grew 2.4 percent per year during 1995-98, more than a percentage point faster than during 1990-95. Faster total factor productivity (TFP) growth contributed an additional 0.63 percentage point, partly reflecting technical change in the production of computers and the resulting acceleration in their price decline. Meanwhile, slowing growth in labor quality retarded ALP 
growth by 0.12 percentage point relative to the early 1990 s, as employers exhausted the pool of available workers (Jorgenson \& Stirion, 2000). Investment in human and nonhuman capital accounts for an overwhelming proportion of the growth of the U.S. economy during the postwar period. Educational investment will continue to predominate in the investment requirements for more rapid growth (Jorgenson \& Fraumeni, 1992).

The rate of change of output per worker increases more rapidly when intangibles are counted as capital, and capital deepening becomes the unambiguously dominant source of growth in labor productivity (Corrado , Charles, \& Daniel, 2006). The rapid expansion and application of technological knowledge in its many forms (research and development, capital-embodied technical change, human competency, and the associated firm-specific co-investments) is a key feature of recent U.S. economic growth (Corrado, Charles, \& Daniel, 2006). Each of the successive periods after 1950 exhibits a downward step in per-capita real GDP growth, with steps downward marked at 1964, 1972, and 1987. The final step downward is not actual data but a 2007 forecast that I made before the financial crisis of growth for the two decades 2007-27.4 Due to the recession and sluggish recovery, the level of U.S. real GDP per capita is currently running 8 percent below the level implied by that forecast made five years ago (Gordon, 2012). The growth of labor input is the sum of growth of hours worked and growth in labor quality (Jorgerson, Gollop, \& Fraumeni, 1991). Labor is important factor for economic growth in developing countries and labor plays a key rule to boost up economic growth through remittance and subsequently foreign exchange reserve and this way macroeconomic is environment relatively strong over time (Chowdhury, Uddin, \& Islam, 2014). Capital and labor are the most important indicator of Economic growth and more than three-fourths of U.S. economic growth during the period 1948-1979 to growth of capital and labor inputs and less than one-fourth to productivity growth (Jorgenson D. , 1099).

The main objective of this study is to investigate the economic performance of the United Sates Economy. This paper has explored economic performance and describes the path that the economy has followed from 1948 to 2015 . It also offered an explanation of why the economy behaves over time. This study forecasted the different level of growth rate and discuss about the business cycle. A few projections of where the economy is headed have been offered. Economic Forecasting is crucial aspect of this study. In this research future economic growth forecast has described in terms of the factors described above was analyzed. This was done by calculating the growth rates for total production labor, as well as capital to show the trend for factors of production. Growth accounting was also used to understand the relationship each factor had on total production. Forecasting was also an important aspect of this paper. The question of what will help or hurt future economic growth in terms of the factors described above was analyzed. ADP can promote the economic growth of an economy which indicates that capital accumulation has plays an important role to accelerate the economy in past years (Uddin, Chowdhury, \& Ahmed, 2015).

The structure of the paper is as follows. After this introduction, section two deals with the data sources and methodology that included definition of the variables and expected relation have been discussed, and it also included different statistical techniques which have been used for this analysis. Later section represents the findings and analysis of the study. Final section represents some concluding remarks and policy implications of the desired study.

\section{Method}

This study is based on the secondary sources of data. These data are collected for the period of 1948 to 2015 and the data for this study are obtained from Bureau of Economic Analysis (of various years) and Federal Reserve Board of Governors. To examine the performance of U.S. Economy, this study used annual time series data for the period of 19452015 for the six variables and these are: Gross Domestic Product (GDP), Real GDP, Compensation of employees (COMP), Full-time equivalent employees (EMP), Net Stock of Fixed Assets and Consumer Durables (CAP) and Capacity utilization rate (UTIL). These six data sets will be examined throughout this paper, and Gross Domestic product (GDP) is the key instrument of economic growth and Real Gross Domestic Product (RGDP) has been used throughout this paper as the measure of U.S economic performance. The remaining four datasets (exclude GDP) are factors of RGDP and used to explain why the economy has experienced recessions and expansions.

The primary objective of this study is to estimate the economic performance of the United Sates. To achieve this objective, the time series Ordinary Least Square regression is used to estimate the model. The functional form of the model is specified as;

i. $Y i=\beta i+\beta i X i+u i$

Where, $\mathrm{Y}$ is the dependent variable, $\mathrm{X}_{\mathrm{i}}$ is the explanatory variables, $U$ is the stochastic disturbance term, and $i$ is the ith observation since the data is time serial. The basic relationship to estimate is economic performance indicators and long-run growth version of equation (i), and is of the following form:

\section{ii. $\mathrm{RGDP}=\mathrm{f}$ (COMP, EMP, CAP, UTIL )}

Equation (ii) is the basic functional form of this model and used different polynomial models to see how economy works over time which included first, second and third order exponential model, lag dependent variable model including dummy variables and linearized the models in the section one to examine the growth rate. In this analysis different dummy variables have been used and a new Capital $(\mathrm{K})$ variable incorporated to modeling and forecasting, and see how economy works during recession.

From the literature, an increase of growth of labor and capital should increase economic growth through higher skill acquisition and higher income. Thus, we expect a priori that 
an increase full time employees and net stock of fixed assets and consumer durables should increase economic growth. The two economic performance indicators (Labor and capital) entered into the model separately in order to determine which indicator is the best channel through which growth variable has most influence on economics growth. This analysis included lag dependent variable into the first order exponential model to find the period to period growth rate.

In order to figure out the economic performance in the U.S., the exponential model used as a method. The sample period for investigation in 1945-2015 the empirical analysis of this study employed annual secondary data, collected from different sources, which are time series data. Most time series data are non-stationary by their nature. If the data is nonstationary the ordinary least square may not be applicable. So for validity of OLS regression we applied unit root test to check stationarity. To test the co-integration of variables, Johansson co-integration approach has been used. This empirical analysis divided in three stages. The first stage, this study used ADF unit root test to test the stationary. In the second stage, the test for co-integration is conducted using Johansson co-integration procedure that is verifies the order of integration of the variables since the various co integration tests are valid only if the variables have the same order of integration and in the final stage, we run the regression for different models which are included in analysis and different figures have been generated for this study.

\section{Results}

\subsection{The Path of the U.S. Economy}

In this analysis real GDP could be used to measure the economic performance or overall growth of the U.S economy. Figure 1 shows that real GDP for the U.S. from 1948 to 2015 adjusted for inflation to represents 2009 dollars. In 1948 the real GDP was $\$ 2020$ billion dollars and the real GDP for 2015 was $\$ 16397.2$ billion dollars. Without adjustment for inflation, GDP for 1948 and 2015 were 274.8 billion dollars and 18,036.6 billion dollars respectively. Using real GDP the U.S. economy has increased its annual production of goods and services more than $811.74 \%$ from 1948 . On the other hand, using GDP it would seem the U.S. economy has increased the production of goods and services by $6563.53 \%$. The second measure would be misrepresentative of the actual difference of quantities produced from 1948 to 2011. Real GDP is used when we want to monitor the growth of output in an economy. Nominal GDP, typically referred to as just GDP, uses the quantities and prices in a given time period to track the total value produced in an economy in that same span of time. Conversely, real GDP tracks the total value produced using constant prices, isolating the effect of price changes. So, real GDP is and accurate gauge of changes in the output level of an economy. Real GDP only accounts for the difference of quantities produced; it is therefore a more precise measure of actual economic growth. Real GDP will be used throughout this paper as measure of the U.S. Economy.

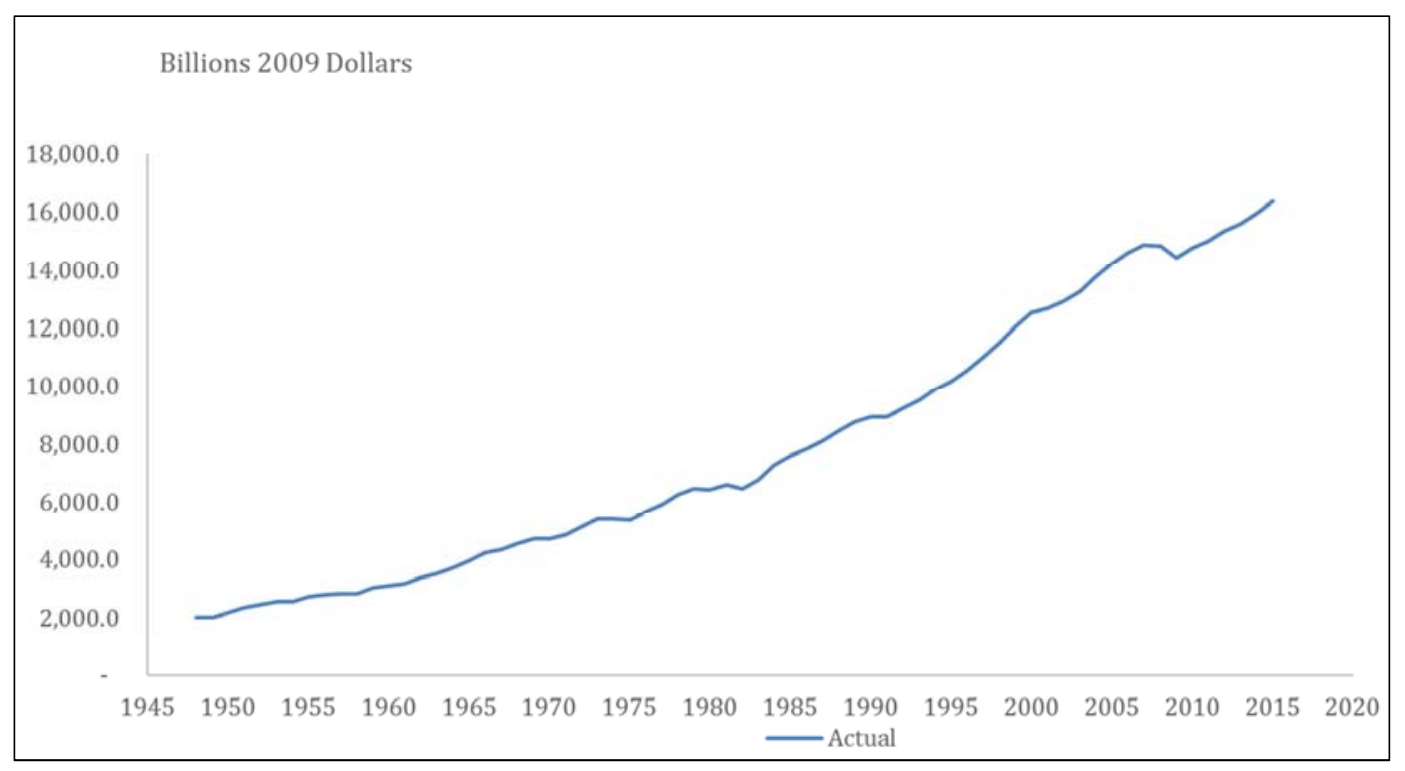

Figure 1. U.S Real Gross Domestic Product Actual 1948-2015.

Figure 1 provides the graphical representation of actual U.S. real gross domestic product form 1948 and 2015 based on the billion dollars of 2009 (base year). These real values are more accurate representation of the U.S Economic growth. This graph shows an upward trend until the period
2009 and there was a slight drop of real GDP in 2009. After 2010, this graph also has upward trend.

To examine the rate of growth, first order exponential model is useful. In this way the research identify the rate of economy of growth and determine the average growth rate. 
The type of growth can be estimated using first order exponential model with implies a constant rate over time.

$$
y_{t}=y_{0} e^{r t}
$$

Equation 1 shows the first order polynomial model which allowed to time variable. In the equation RGDP is represented by $y_{t}, y_{0}$ is equal to the first year of data (1948 for this analysis) in the time period $t$ and $r$ as the constant growth rate for this time period. Equation 1 has the variables $r t$ as exponents; this indicates that there is a non-linear relationship between real GDP and the constant rate of growth $\&$ the rate period. The variable $t$ takes on consecutive, discrete who number values start from o for the initial time period and increasing until the last periods (our model takes 35 years of consecutive time periods). The number e is mathematical term which equivalent to approximately 2.71 when $\mathrm{t}=0$, the variable $\mathrm{A}$ is interpreted as the predicted values of real GDP in the initial period 0 .

In order to fit the model to the RGDP a linear relationship between $y_{t}$ and $\mathrm{t}$ must be embellished equation ${ }^{1}$. This process of linearization results in a First Order Linearized Model and can be done by taking natural log both hand of the equation one.

$$
\ln \left(y_{t}\right)=\ln \left(y_{0}\right)+r t
$$

In this Linearized exponential model $r$ is the coefficient implying that there is a linear relationship between $\mathrm{r}$ and $\ln \left(y_{t}\right)$. Regressing the natural log of Real GDP $\left[\ln \left(y_{t}\right)\right]$ on the time variable $t$, we obtained the estimated model is ${ }^{2}$ :

$$
\ln \left(y_{t}\right)=\begin{gathered}
7.7168 \\
(0.013) * * *
\end{gathered}+\begin{gathered}
0.03195 t \\
(0.0003) * * *
\end{gathered} ; \mathrm{R}^{2}=0.9906
$$

If the first order exponential model was the best fit then U.S. RGDP would grow at a constant annual average rate of 3.20 percent. Standard error is reported below the coefficient of this model and statistical significance reported using asterisk sign3. This model indicates, variable is statistically highly significant at $1 \%$ level of significance and it has high $\mathrm{R}^{2}$ value which is a sign of good fitted model. This high $\mathrm{R}^{2}$ represents this model explains $99.06 \%$ of the variability of the response data around its mean.

Examining Figure 1, one can see that while the U.S. RGDP has a general upward slopping curve, though it is not constant or smooth; this indicates a growth rate that is not incrementally constant. To find the best fitted curve higher order exponential models can be explored. A higher

1 A linear relation relationship is established by taking the natural log of both sides of the equations (eq.) and the applying the sum rule to (eq-1) results in $\ln \left(y_{t}\right)=\ln \left(y_{0}\right)+\ln \left(e^{r t}\right)$, apply the power rule $\ln \left(y_{t}\right)=\ln \left(y_{0}\right)+r t \ln (e)$,

2 The standard errors for the both the intercept 0.013 and the coefficient 0.0003 are both less than 0.01 and therefore $99 \%$ confidence interval of the coefficient not being 0 standard errors between $0.1 \& 0.05$ and receive one asterisk and indicate that the model is at least 90 percent confident of the coefficient not being 0 , errors between $0.05 \& 0.01$ receive two asterisks and have a confidence level of at least 95 percent, finally standard errors less than or equal to 0.01 have the highest level of confidence at 99 percent.

$3 * 10 \%$ level of significance $* * 5 \%$ level of significance and $* * * 1 \%$ level of significance. exponential model can be useful because it does not restrict the growth rate to be constant, rather they allow for more variation in the growth rate and can fit the data better. Experimenting with second and third order models, this study found that a second order-linearized model is the best fits model.

This study operated higher order exponential regression analysis by taking two models and ruled out one model from our final analysis because the third order variable is not statistically significant. So, reduced it to second order exponential model and this research found the model to be best fitted among all of them. Regresses $\ln \left(y_{t}\right)$ on $t$ and $t^{2}$, we obtained the estimated model:

$$
\begin{gathered}
\ln \left(y_{t}\right)=\ln \left(y_{0}\right)+r_{1} t+r_{2} t^{2} \\
\ln R G D p=\begin{array}{c}
7.60 \\
(0.012056) * * * *
\end{array}+\begin{array}{c}
0.042 t \\
(0.00083) * * *
\end{array} \\
-\begin{array}{c}
0.00015 t^{2} \\
(0.000012) * * *
\end{array} ; \mathrm{R}^{2}=0.9971
\end{gathered}
$$

This model indicates real GDP grew by 7.6 percent is 1949 and continued to grow at a decreasing rate. It also indicates that real GDP is growing but at a decreasing rate. It has shown that's all the variables are statistically significant and model has high $\mathrm{R}^{2}$ value which represents that $99.71 \%$ of the variation explained by the model.

Figure 2 shows that real GDP and it included actual, first and second order regression models. This figure consist of three line, Actual line, first order exponential model lie and second order exponential model line. It can be shown that first order exponential model line is closely follows actual line until it reaches to 2005 period of year and after 2005 it dramatically deviated from actual line which indicated RGDP growing faster after 2005. However, second order exponential model is more closely follows the actual line throughout the period between 1948 and 2005 but after 2005 variance looks more tighter compared to first order exponential model. The first order exponential model shows that this model could explain $99.06 \%$ of the movement of the Real GDP. In another word it can be explained $99.06 \%$ of the variation in the data. But second order polynomial model can explain approximately $99.71 \%$ of the movement of real GDP.

\subsection{U.S Business Cycle}

The business cycle is the natural rise and fall of economic growth that occurs over time. The cycle is a useful tool for analyzing the economy. It can also be helpful to make better financial decisions. Business cycles are identified as having four distinct phases: peak, trough, contraction, and expansion. Business cycle fluctuations occur around a longterm growth trend and are usually measured by considering the growth rate of real gross domestic product. This analysis used de-trended data series which is the deviation of actual data series from the model. This study observed heteroscedasticity when plotted this data because there is a systematic change in the deviation. But business cycle 
detrended model reduces the heteroskedasticty which is shown in figure 3. This study also used first order exponential model from figure 2 to see the departure from actual data. It can be seen that during the economics expansion there was a boom but in the time of recession economy was sluggish. When economy was in boom, there is peak and during recession, there is a trough. In this study business cycle is counted one full peak and one full trough. Figure 3 shows the business cycle from 1948 to 2015.

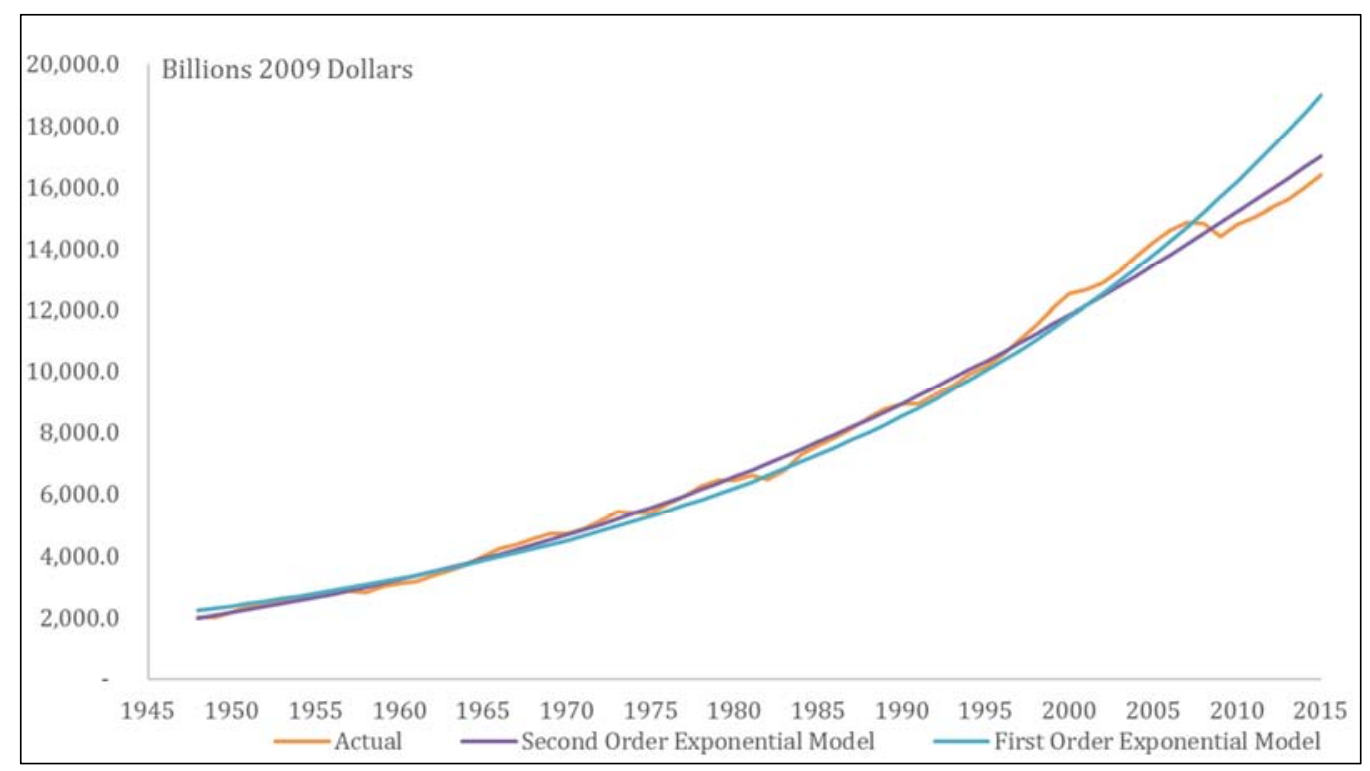

Figure 2. U.S Real GDP: Actual and Models 1948-2015.

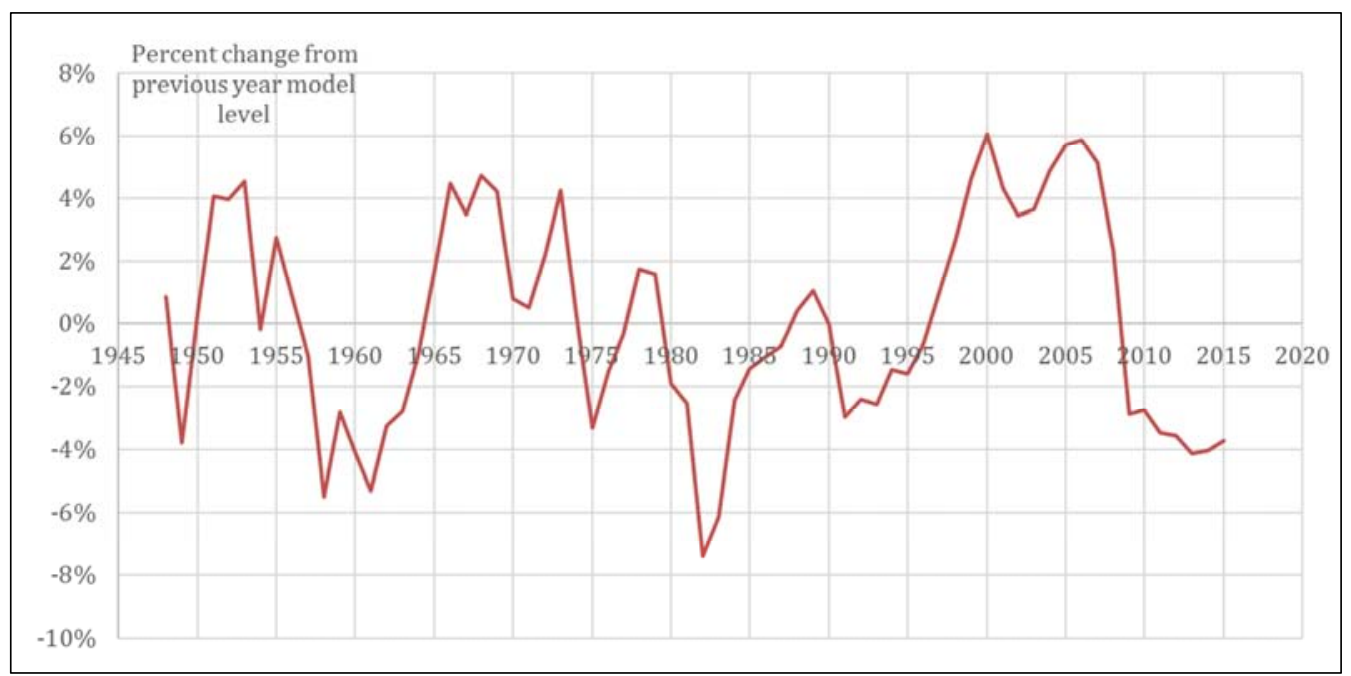

Figure 3. U.S Real Gross Domestic Product-Detrended Model 1948-2015.

From figure 3, it is observed that there have been six full business cycle between 1948 and 2015 currently U.S economy is undergoing another trough; and presented them in table 1 which includes each cycle, trough, peak and magnitude. The U.S economy was experienced the worst trough during the period of 1980 to 1987 which lasts more than 7 years.

Table 1. Business Cycle

\begin{tabular}{lllllll}
\hline Cycle & Duration & Peak & Amplitude & Trough & Duration \\
\hline $1948-1950$ & 3 & 1948 & - & $1949-1950$ & 1 \\
$1951-1954$ & 4 & $1951-1953$ & Medium & 1954 & 1 \\
$1955-1964$ & 10 & $1955-1956$ & Medium & $1957-1964$ & 7 \\
$1965-1976$ & 12 & $1965-1975$ & Medium & $1975-1976$ & 1 \\
$1977-1987$ & 11 & $1977-1979$ & Small & $1980-1987$ & 7 \\
$1988-1996$ & 9 & $1988-1990$ & Small & $1991-1996$ & Medium & Medium \\
$1977-? ? ? ? ?$ & & $1997-2008$ & Medium & $2009-? ? ? ?$ & Medium & Medium \\
\hline
\end{tabular}




\subsection{Forecasting Future U.S. Production Levels}

Figure 4 displays the Actual and forecasted model. This figure shows the real GDP and a forecast of the next 20 years starting from 2015 to 2035 . The second order regression $\mathrm{Y}$ model (shown in equation 4) is used to estimate the forecast real GDP levels. The second order exponential model is kind of smooth curve that means there is no significant fluctuation in this curve. After 2000, this curve below the actual curve and then from 2010 this curve goes above the actual curve. In 2015 actual and real GDP was equal to 16.397 trillion compared with estimated real GDP of 16.487 trillion. In 2016, the first year forecast, real GDP was predicted to be 17408.3 billion, and grows to 24918.2 billion by 2035 .

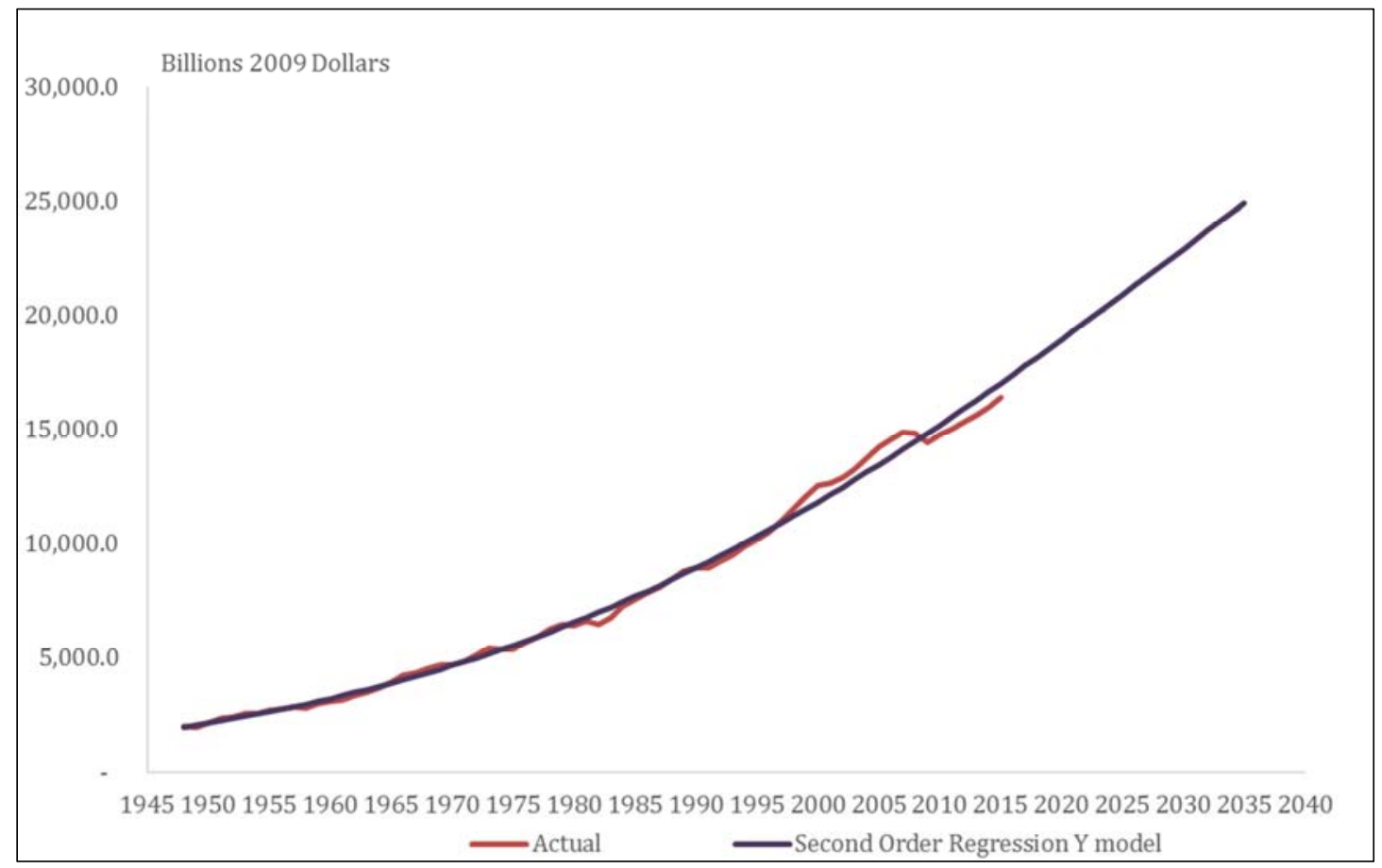

Figure 4. U.S Real Gross Domestic Product: Actual and Forecasts 1948-2035.

\subsection{Modeling and Forecasting Growth Rates of U.S. Production, Employment and Capital}

Modeling of growth rates can be used to determine if there are trends with and what the trends are. Two important questions that can be answered by trend analysis are: is the growth rate deciding or accelerating? What is the pace of the decline and acceleration? With those two important questions answered forecasting of future rates can be interpolated from the trends. Figure 5 displays the average, actual, and modeled growth rates for U.S. Real GDP from 1949-2015 along with 20 year forecasted average and modeled growth rates.

The first order exponential model can be used to find a period-to-period rate of growth. To obtain growth rate for each period a log difference formula is used ${ }^{4}$ :

$$
\ln \left(y_{t}\right)-\ln \left(y_{t-1}\right)=r
$$

The natural log difference, obtained from the first order exponential model, is a measure of the growth rate from one period to another, represented in equation (6) by $r$.

4 If $y_{t}=y_{0} e^{r t}$ and $y_{t-1}=y_{0} e^{r(t-1)}$ the natural $\operatorname{logs}$ of both equations are $\ln \left(y_{t}\right)=\ln \left(y_{0}\right)+r(t-1)$ respectively, therefore $\ln \left(y_{t}\right)-\ln \left(y_{t-1}\right)=\ln y_{0}+$ $r t-\ln \left(y_{0}\right)+r(t-1)$ simply and the difference from year $(\mathrm{t})$ to $(\mathrm{t}-1)=\mathrm{r}$, the rate of growth for that period.

$$
g_{y t}=a_{0}+a_{1} t
$$

Equation (7), the first order model where $g_{y t}$ is the average growth rate determined from regressing the growth rate of each period $a_{0}$ on the time period $a_{1} t$. This first model will be used to determine the average growth rates for U.S. Real GDP, Labor, and Capital. This type of model can be considered optimistic because it does not take recessionary periods into account. This estimated model is:

$$
g_{y t}=\begin{gathered}
0.042 \\
(0.005) * * *
\end{gathered}-\begin{gathered}
0.0003 t \\
(.0001) * *
\end{gathered} ; \mathrm{R}^{2}=0.0801
$$

The regression results indicate the average growth rate was 4.2 percent in 1949 and declines 0.03 percentage points per year but economy is growing at a decreasing rate. The $\mathrm{R}^{2}$ value determines that this model can explain only 8.01 percent of the variation.

If we want to show recessions on the economy, we can include a dummy variable. Including the dummy variable we can show the better effect of the recession on the economy and this dummy variable is known as indicator variables. For any period that the growth is positive the variable is 0 and for negative periods the variable is 1 . In other word, this study 
will identify recession with 1 if the economy is and recession or 0 if not in the recession. The resulting equation is given below.

$$
g_{y t}=a_{0}+a_{1} t+a_{2} D
$$

The result of the model accounting for recessions is:

$$
g_{y t}=\begin{gathered}
0.0521 \\
(0.004) * * *
\end{gathered}-\begin{gathered}
0.0004 t \\
(.0001) * *
\end{gathered}-\begin{gathered}
0.048 D \\
(0.005) * * *
\end{gathered} ; \mathrm{R}^{2}=0.6279
$$

This second order polynomial model indicates that the Real GDP grew at an average rate of 5.21 percent in 1948 and that rate is declining 0.04 percentage points each year, with an additional loss of 4.8 percentage points in a recessionary year. The $\mathrm{R}^{2}$ value of 62.79 percent indicates that taking recessionary periods into account increases the models explanation of variance from the trend in the data.
The second order polynomial model captures more variation than $1^{\text {st }}$ order polynomial model.

Both models indicate a growth at a declining rate for real GDP. The predicted values of output growth for the 2035 are 1.4 percent and 1.8 percent with the optimistic and recessionary models.

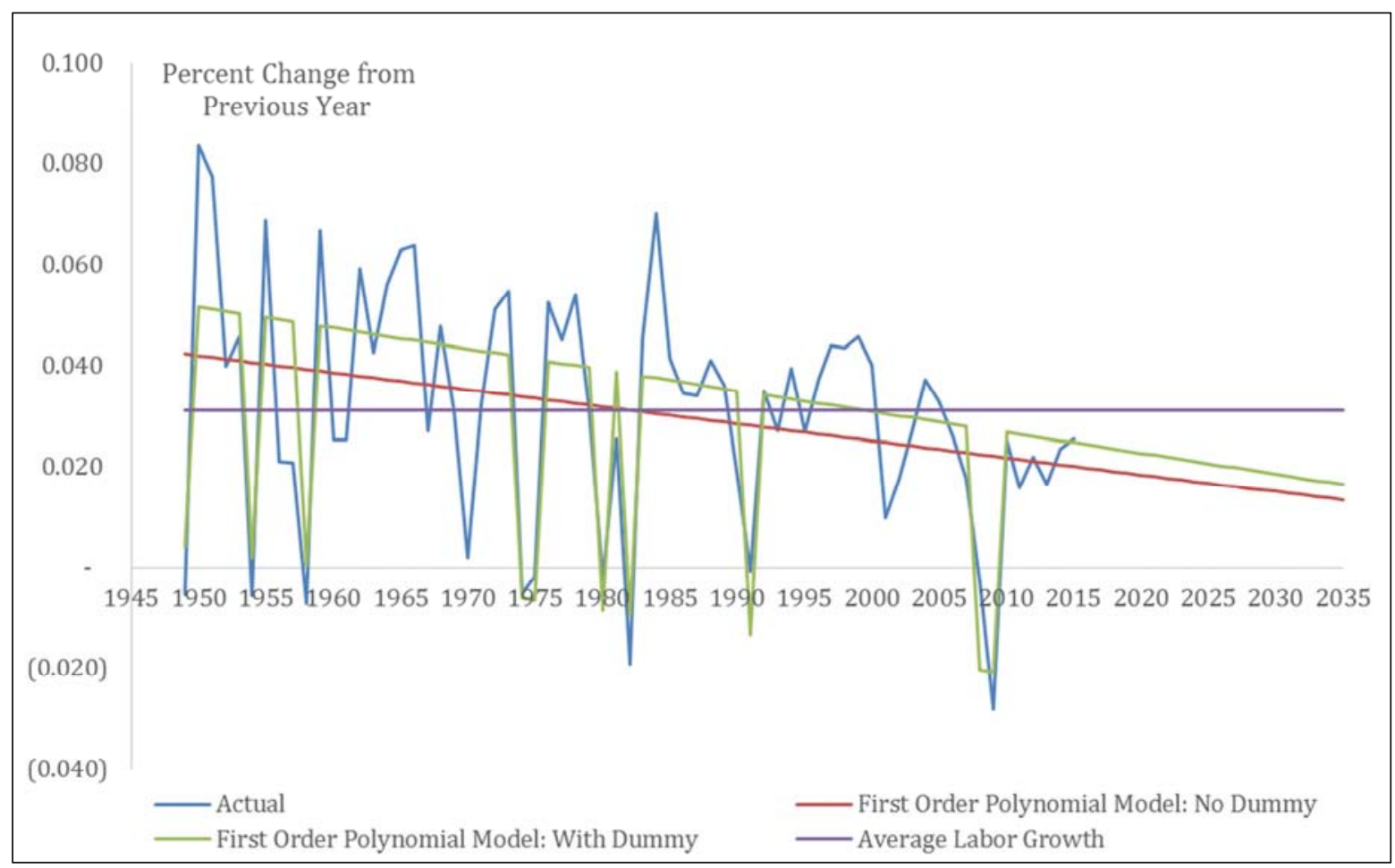

Figure 5. U.S Real Gross Domestic Product Growth Rate with Forecast: 1949-2035.

Figure 6 and 7 display actual, average, and modeled growth rates for labor, and capital and with the projected values out of 20 years for average and modeled growth rates. The models are based on equations 7 and 9 .

The result for the optimistic growth of the labor market is:

$$
\begin{gathered}
g_{l t}=\begin{array}{c}
0.021 \\
(.0053) * * *
\end{array}-\begin{array}{c}
0.0002 t \\
(.0001) * *
\end{array} ; \mathrm{R}^{2}=0.023 \\
g_{l t}=\begin{array}{c}
0.029 \\
(0.004) * * *
\end{array}-\begin{array}{c}
0.0002 t \\
(.0001) * *
\end{array}-\begin{array}{c}
0.0424 D \\
(0.006) * * *
\end{array} ; \mathrm{R}^{2}=0.4897
\end{gathered}
$$

Meaning that labor is growing at an average rate of 2.1 percent and that growth rate declines by 0.02 percentage points each year. The $\mathrm{R}^{2}$ value indicates that only 2.3 percent of the variation is explained by the model.

The result for the labor growth model accounting for

The recessionary model reports an average growth rate in employment to be 2.9 percent that is slowing at a rate of 0.02 percentage points per year and by an additional 4.2 percentage points in the recessionary periods. The decline of the growth rate in the model is less than the decline of the growth rate in the optimistic model. The $\mathrm{R}^{2}$ value indicates that 49 percent of the variation of the data from the trend is explained by this model. 


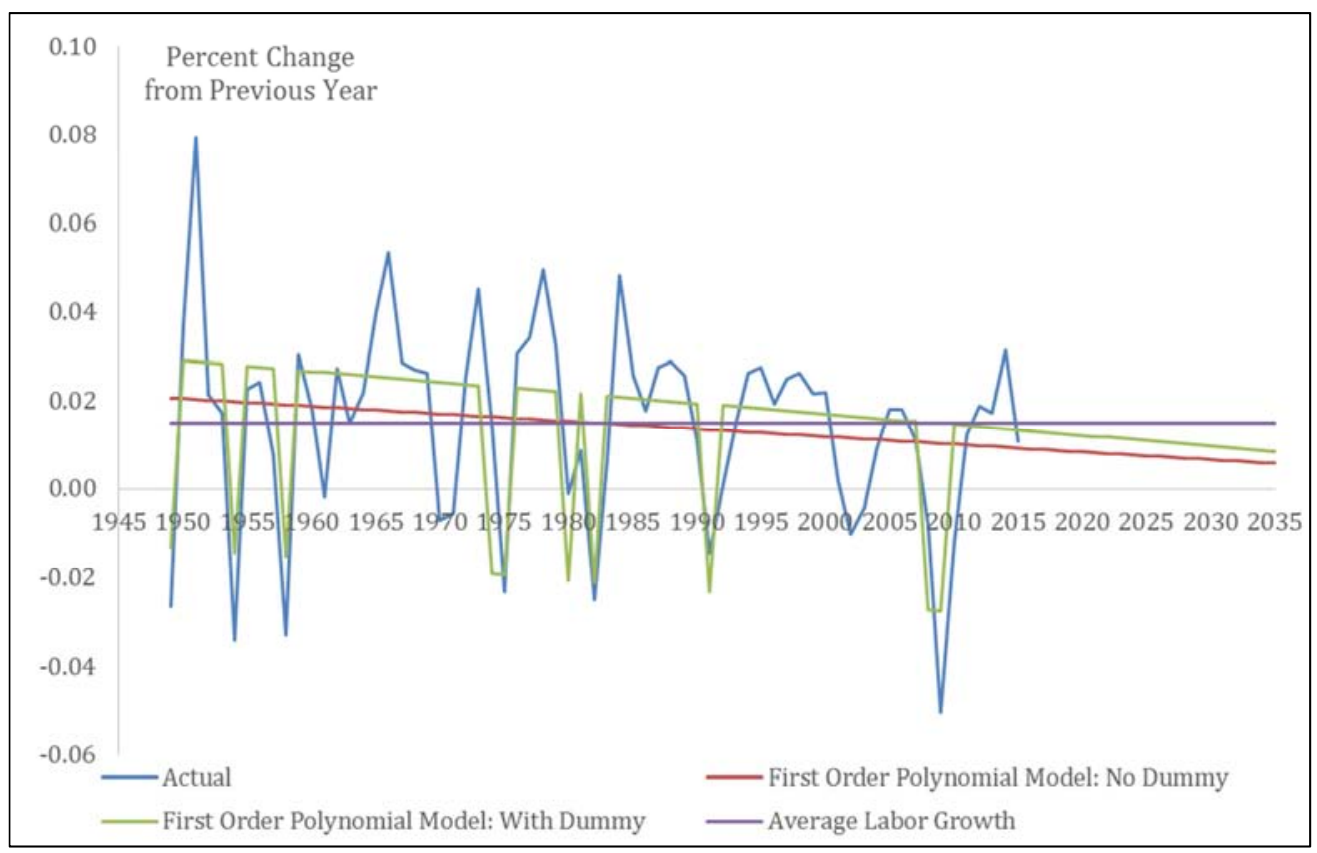

Figure 6. U.S Labor Growth Rate with forecast 1949-2035.

The result for the optimistic growth of capital model is:

$$
g_{k t}=\begin{gathered}
0.037 \\
(0.015) * * *
\end{gathered}-\begin{gathered}
0.0002 t \\
(.0004) * *
\end{gathered} ; \mathrm{R}^{2}=0.002299
$$

An annual average growth rate of 3.7 percent for capital is reported as well as a 0.01 percentage points decline per year. The $\mathrm{R}^{2}$ value indicates that this model explains only 0.22 percentage points from the model in the data.

The results for the capital growth model accounting for recessionary period is:

$$
g_{k t}=\begin{gathered}
0.058 \\
(0.009) * * *
\end{gathered}-\begin{gathered}
0.0003 t \\
(.0002) * *
\end{gathered}+\underset{(.010) * * *}{0.104 D} ; \mathrm{R}^{2}=0.347
$$

The model reports an annuals average growth rate of 5.8 percent with a decline of 0.03 percentage points per year with an additional decline of 1.04 percent in recessionary periods. The $\mathrm{R}^{2}$ value indicates that 34.7 percent of the variation in the data from the trend is explained by the model.

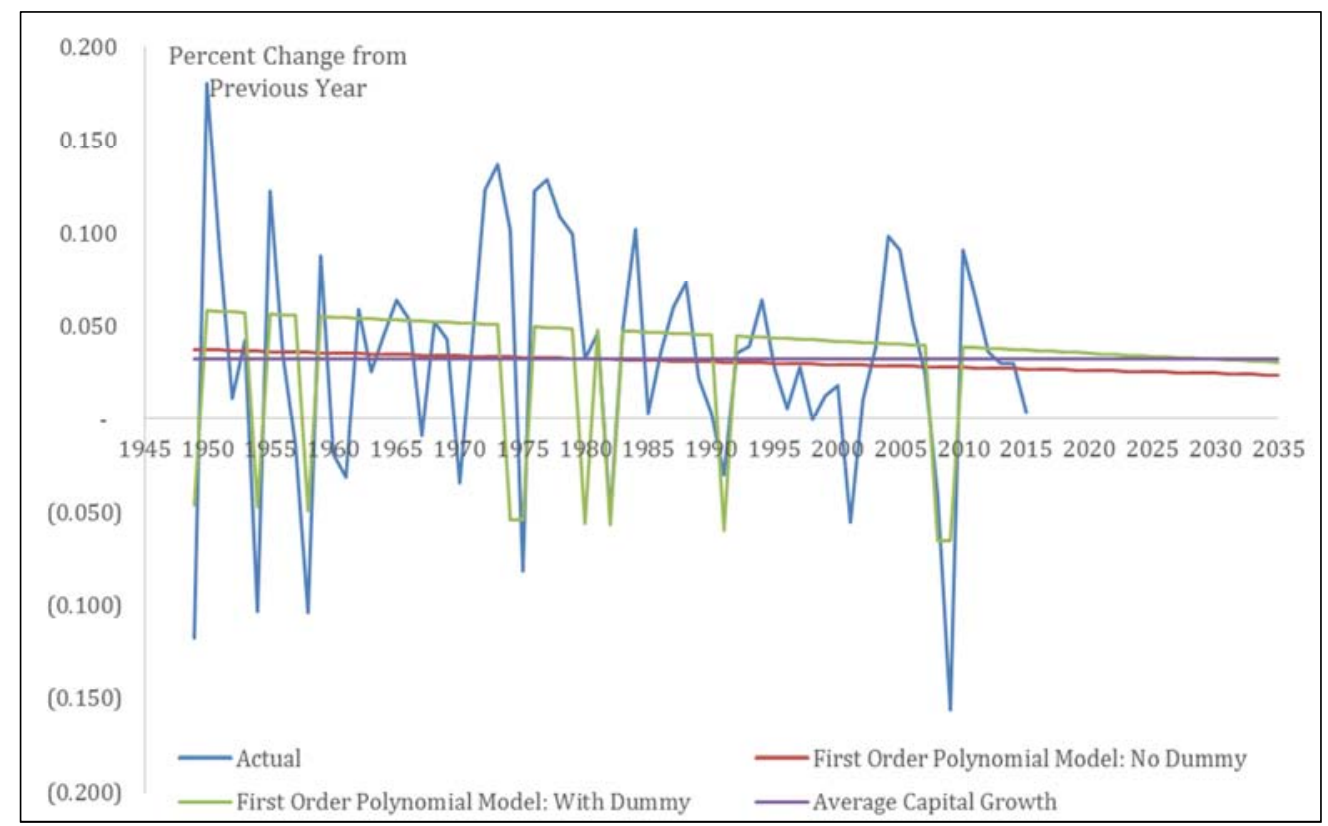

Figure 7. U.S. Capital Growth Rate with Forecast 1949-2035. 
The variance in the data from the trends for RGDP, labor, and capital seem to be better explained when recessionary periods taken into consideration. For the purposes of projecting growth rates of each series, an average of the optimistic and recessionary models may be calculated. Unforeseen occurrences can severely alter these projections for the better, or worse.

\subsection{Explaining and Forecasting Economic Growth}

The economic growth of any country measured by one popular model that represents factors of output is the CobbDouglas production function. This model represents output dependent upon technical change, labor and capital. For this study, real GDP or output has been used to measure the growth of the U.S. Economy. The factors of RGDP are technology, labor, and capital. A commonly used model is the Cobb Douglas Production Function:

$$
Y=(A L)^{\beta} K^{\alpha}
$$

Where $\mathrm{Y}$ represents output and is the product of $\mathrm{A}$ the level of technology or productivity, $\mathrm{L}$ labor, $\mathrm{K}$ capital, $\beta$ is the elasticity of output with respect to capital. Applying the Cobb Douglas Production to determine the estimation of the growth rate of output with respect to the growth of labor, capital, and technology, the model must first be linearized ${ }^{5}$ (include footnote) and then derived in terms of time (t). Now we regress the the growth of techninlogy, growth of labor and the growth of capital. The resulting estimation of the model is:

$$
\begin{gathered}
g Y=\beta g A+\beta g L+\beta g K \\
g Y=\begin{array}{c}
0.018 \\
(0.002) * * *
\end{array}+\begin{array}{c}
0.632 g L \\
(0.102) * *
\end{array}+\begin{array}{c}
0.110 g K \\
(0.036) * * *
\end{array} ; \mathrm{R}^{2}=0.7271
\end{gathered}
$$

The linearized growth model ${ }^{6} .1$ assume that $\mathrm{Y}, \mathrm{A}, \mathrm{L}$, and $\mathrm{K}$ change with time, $\beta$ and $\alpha$ are the coefficients of technology, labor, and capital and thus constant. This model indicates the elasticity of capital with respect to output is 0.110 , and the elasticity of labor with respect to output is.632; meaning for every one unit of increase to labor or capital, output increase by 0.632 or 0.110 respectively. The value of the intercept indicates the contribution of technology to output. The result indicates, a ten percent increase change in capital $(\mathrm{K})$ leads to a $1.1 \%$ percent change in production. It also shows, a ten percent change in labor (L) leads to a 6.3 percent change in production.

The total average growth of output over time is approximately 3.13 percent. To understand the effect of each variable in the output composition, growth accounting is utlilized. Using the model estimates presented above, the average growth rates for labor and capital are plugged in:

$$
0.0313=0.01824+.632458(0.015)+0.11(0.0321)
$$

Then each value on the right side of the equation is divided by the left side and multiplied by 100 to obtain percentages.

Table 2. Accounting of Growth

\begin{tabular}{llll}
\hline \multicolumn{2}{l}{ Growth Accounting } & & \\
\hline gY & gA & gL & gK \\
\hline $3.13 \%$ & $1.8 \%$ & $0.9 \%$ & $0.4 \%$ \\
$100 \%$ & $57.5 \%$ & $28.8 \%$ & $12.8 \%$ \\
\hline
\end{tabular}

The output growth model gives an important insight into the actual effects of technology, labor, and capital. 57.5 percent of output growth depends on technology, 28.8 percent depends on labor, and 12. Percent depends on capital. It can be observed that technology has the greatest impact on output and that labor outweighs capital. Since technology seems to be the most significant factor of output, it would be beneficial to model its growth. The following model can represent growth of technology:

$$
A=a_{0} e^{r_{1} t}
$$

Applying previous techniques, taking the natural log and then deriving, a linear relationship between $\mathrm{A}$ and $\mathrm{r}$ can be found and represents technology growing at a constant rate over time. This model describes how level of technology A is affected by time ${ }^{7} \mathrm{t}$.

Extending the model to include changes in the growth rate over time would be represented as:

$$
A=a_{0} r^{r_{1} t+r_{2} t^{2}}
$$

When linearized and derived this model indicates that the only time technology has a constant growth rate is when $\mathrm{t}=0$. Extending this model further for can be represented as 8:

$$
A=a_{0}+r^{r_{1} t+r_{2} t^{2}+r_{3} t^{2}+r_{4} t^{4}}
$$

The result of substituting the linearized technology change from equation (20) into equation (15) for technology A, creates a structural model:

$$
g_{y}=a_{0}+a_{1} t+\beta g_{L}+\alpha g_{k}
$$

The estimation result of the model is:

$$
\begin{gathered}
g_{y}=\begin{array}{c}
.0258-003) * * *-0002 t \\
(.0001) * * *
\end{array}+\frac{.583 g L}{(.097) * * *} \\
+\begin{array}{l}
.1196 g K \\
(.033) * * *
\end{array} ; \mathrm{R}^{2}=.7594
\end{gathered}
$$

\footnotetext{
$5 Y=A^{\beta} L^{\beta} K^{\alpha}$

$6 \ln Y=\ln \left(a^{\beta} L^{\beta} K^{\alpha}\right), \ln Y=\beta \ln A+\beta \ln L+\alpha \ln K, \frac{d Y}{Y}=\beta \frac{d A}{A}+\beta \frac{d L}{L}+\alpha \frac{d k}{K}$, $g Y=\beta g A+\beta g L+\alpha g k$
}

$7 A=a_{0} e^{r_{1} t}, \ln A=\ln a_{0}+r t, g A=0+r$
$8 g A=r_{1}+2 r_{2} t+3 r_{3} t^{2}+4 r_{4} t^{3}$ (linearized and derived) 


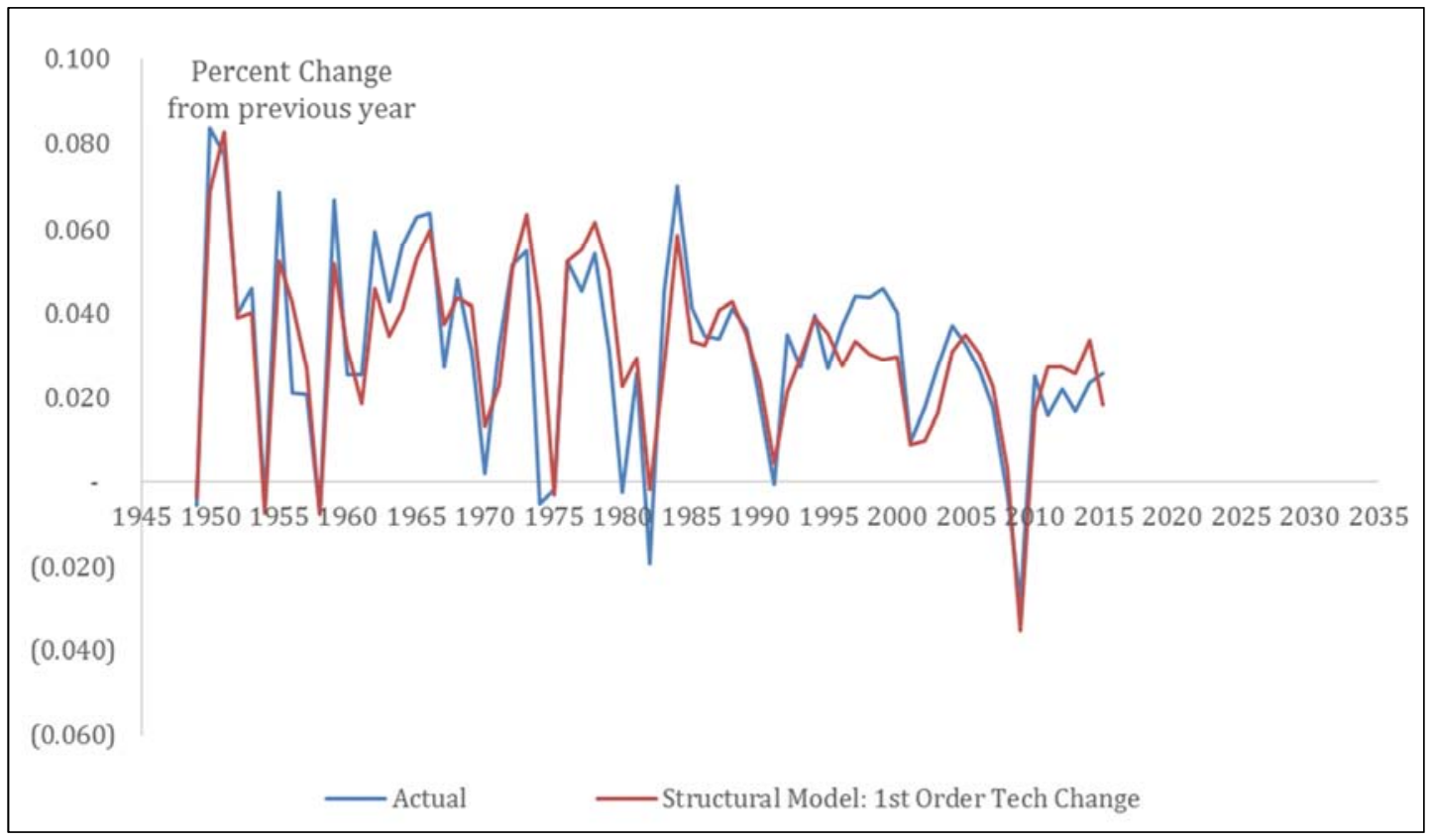

Figure 8. U.S. Output Growth Rate.

Taking the model from equation 20 and substituting for $\mathrm{A}$ in the linearized Cobb Douglas Function creates a $3^{\text {rd }}$ order structural forecast model:

$$
g_{y}=a_{0+} a_{1} t+a_{2} t^{2}+a_{3} t^{3}+\beta g L+\alpha g K
$$

The result of estimating this model is:

$$
g Y=\frac{.034}{(.005) * * *}-\frac{.002 t}{(.0007) * * *}+\frac{.00005 t^{2}}{(.00002) * * *}-\frac{.0000004 t^{3}}{(.0000002) * * *}+\frac{.58 g L}{(.09) *}+\frac{.13 g K}{(.033) * *}
$$

The model estimation indicates a strong relationship between the growth of output with respect to the growths of technology, labor, and output. The $\mathrm{t}$ values were less significant.

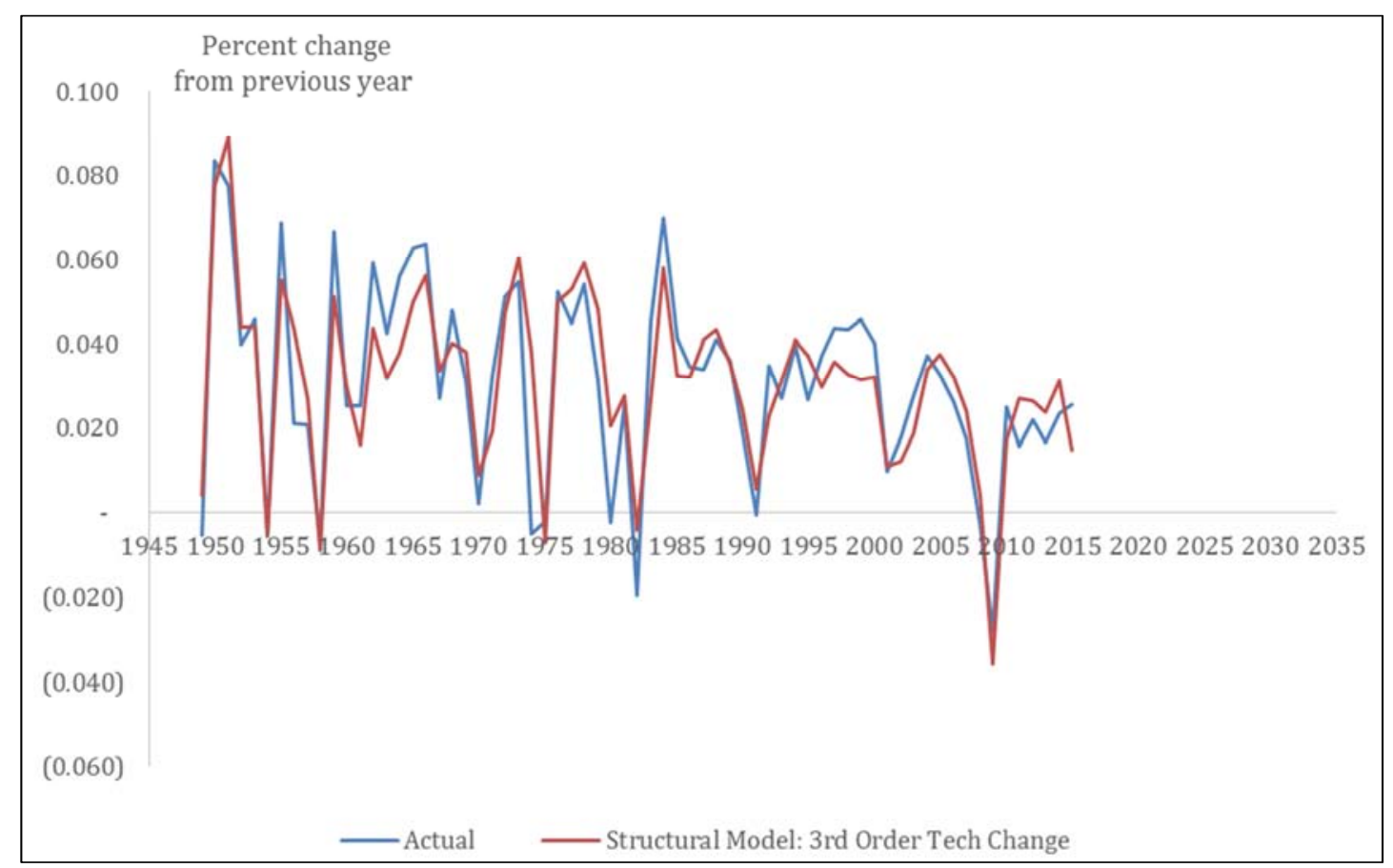

Figure 9. U.S. Output Growth Rate 1949-2015. 
Figure 9 shows the percent change in RGDP as well as the structural model. The structural model with no change in the growth rate of technology:

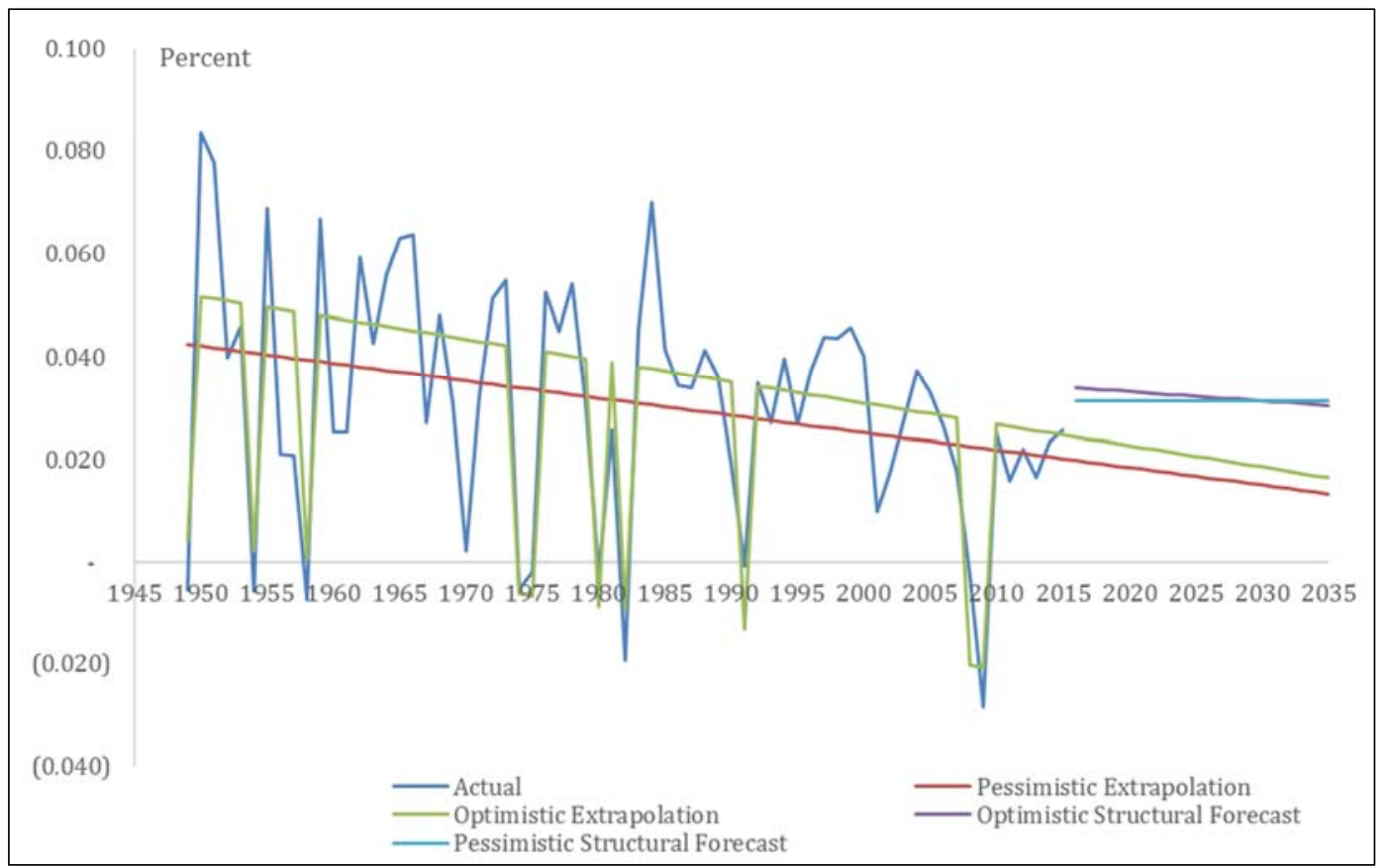

Figure 10. U.S Real Gross Domestic Product Growth Rate Actual and Forecasts 1949-2035.

Figure 10 included the structural model with no technical change with interpolating to a forecast, for constant technical change model from equation. Figure 10 also shows different predictions of the growth rate of GDP varying with different growth rates for technology. This graph is apparent that all the predicted trends are still downward sloping suggesting the growth rate for GDP will continue to decline.

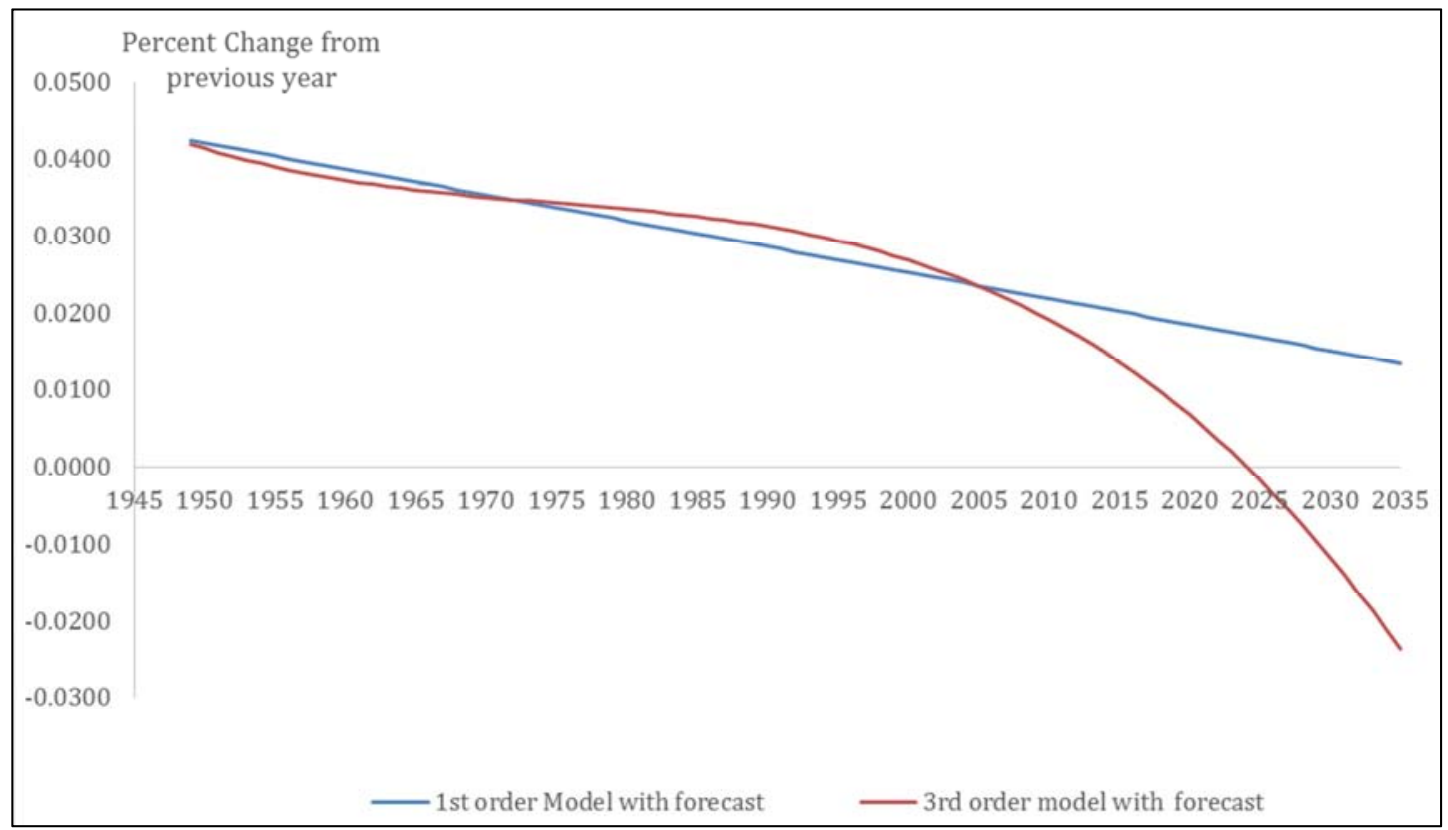

Figure 11. U.S Technological Growth Rate Models with Forecast 1949-2035.

Figure 11 provides a visual representation for modeled technology growth rates. While the third order model is significant in all terms, it weighs the recent recession too heavily, we wouldn't bet my job on that forecast. The first order model with a constant rate of technical change is a more preferable way to see the future. Again taking an average of those two forecasts might provide the best picture of the future growth rate of technology. 


\subsection{Using Economic Theory to Refine the Structural Forecast}

Firms profit accelerate the economic growth of an economy, it could be a good indicator for accelerating growth. The profit level can be denoted equation (25) where $\mathrm{P}$ is the price level, $\mathrm{Y}$ is level of production which is denoted by GDP, $\mathrm{W}$ is the wage level, and the labor force is denoted by L. In short profits are the prices of GDP minus the wages paid to laborer and the production level is given by $Y=$ $(A L)^{\beta} K^{\alpha}$, then the labor share of output $W L / P Y$ must equal the elasticity of output with respect to labor $\beta$ when profits are maximized. PY would be the nominal GDP will WL (wage bill) is the compensation of employees.

$$
\begin{gathered}
\pi=P Y-W L \\
Y=(A L)^{\beta} K^{\alpha} \\
\pi=\mathrm{P}(A L)^{\beta} K^{\alpha}-W L
\end{gathered}
$$

Firm wants to maximize profit by choosing labor level, then the share of output paid to labor WL/PY must equal the parameter $\beta, \beta$ is labor share of output.

$$
\beta=\frac{W L}{P Y}
$$

We want to estimate the rate of technical change $g_{A}=\frac{A^{\prime}}{A}$, and the elasticity of output with respect to labor $\alpha$, in this case assumed profits are maximized. To do this, first converted the production relationship $Y=(A L)^{\beta} K^{\alpha}$ into a relationship of growth rates, letting all variables change except $\alpha$ and $\beta$. After converting the production function obtained:

$$
\begin{gathered}
g_{Y}=\beta g_{A}+\beta g_{L}+\alpha g_{K} \\
g Y-\beta g L=\beta g A+\alpha g K
\end{gathered}
$$

$$
\mathrm{gY}-0.56 \mathrm{gL}=0.56 \mathrm{gA}+\alpha \mathrm{gK}
$$

This equation is used to predict the model of $\mathrm{gY}-0.56 \mathrm{gL}$ on $\mathrm{gK}$

$$
\begin{gathered}
\mathrm{gY}-0.56 \mathrm{gL}=0.0187+0.131 \mathrm{gK} \mathrm{R}^{2}=0.3183 \\
(0.0017)^{* * *}(0.0239)^{* * *}
\end{gathered}
$$

The estimated coefficient of the mode is 0.0187 , which means the base technology level for GDP is currently 0.0187 , and contribution of capital growth is 0.131 percent. These coefficients can be compared to be ones obtained in the explaining economic growth section equation (16). Equation (29) has considered the better estimator of the growth rate of GDP because it works under the assumption that all firms profit maximize. The restricted variable for the growth of labor of 0.55 means that if labor increases by one percent then output increases in productivity. Compared with the growth rates obtained in equation (29) labor is more productive, meaning that the other inputs do not have to be as large to have as large of an effect of output.

Allow for flexibility in the rate of technical change by assuming $\mathrm{A}=\mathrm{a}_{0} \mathrm{e}^{\mathrm{r}_{1} \mathrm{t}+\mathrm{r}_{2} \mathrm{t}^{2}+\mathrm{r}_{3} \mathrm{t}^{3}+\mathrm{r}_{4} \mathrm{t}^{4}}$ which implies a rate of technical change $g_{A}=a_{1} t+a_{2} t^{2}+a_{3} t^{3}$. Later combined output growth rate model and rate of technical change model to obtain

$$
\begin{gathered}
g_{Y}=\beta a_{1} t+\beta a_{2} t^{2}+\beta a_{3} t^{3}+\beta g_{L}+\alpha g_{K} . \\
g_{Y}=.56 a_{1} t+.56 a_{2} t^{2}+.56 a_{3} t^{3}+.56 g_{L}+\alpha g_{K} .
\end{gathered}
$$

An estimate of the parameter $\beta$ was obtained by taking the average the compensation level of employees divided by the gross domestic product for the years 1948-2015. This average, 0.56 , can now be used as the estimate for $\beta$.

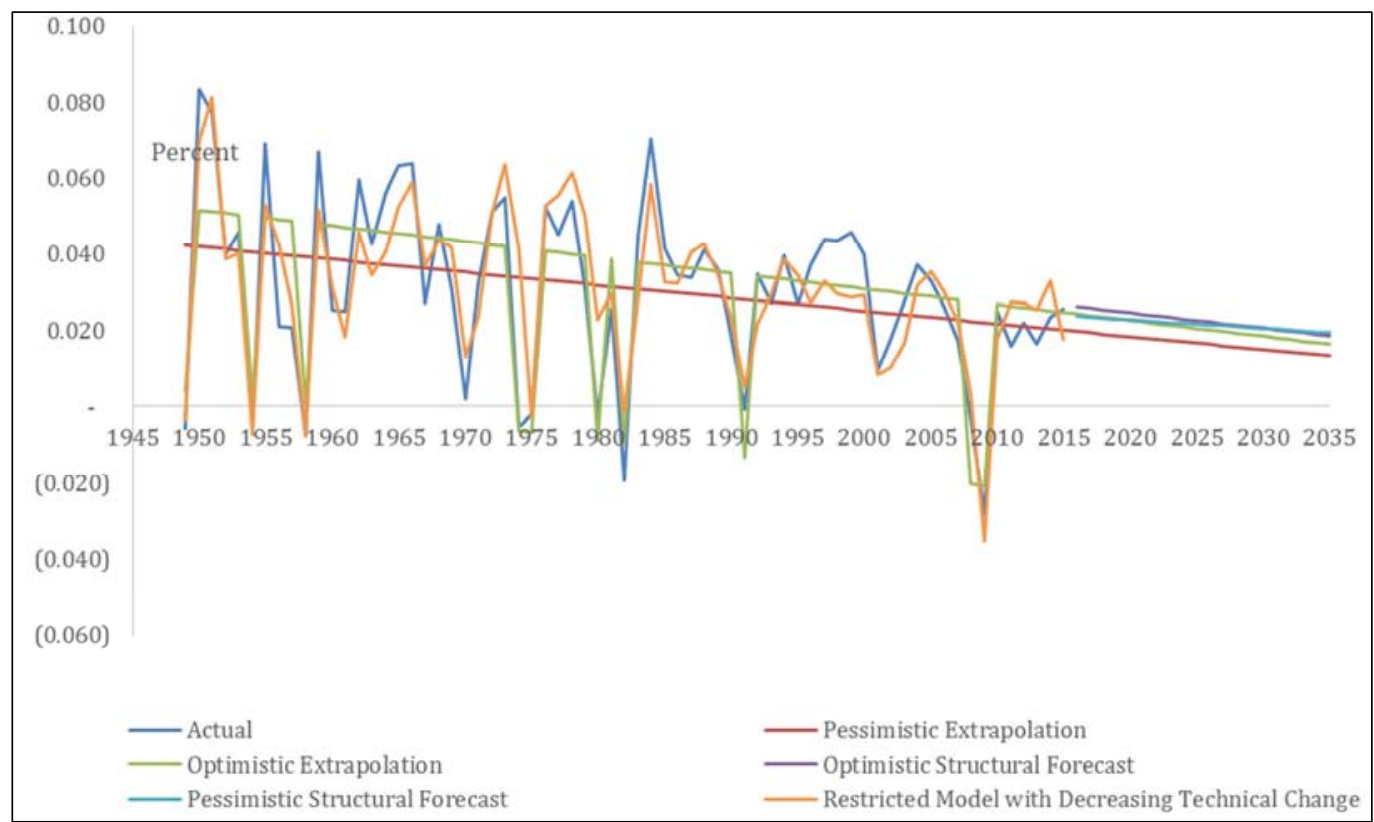

Figure 12. U.S Real Gross Domestic Product Growth Rate Actual and Forecasts 1949-2035. 


\section{Discussion}

In 1948 the real GDP was $\$ 2020$ billion dollars and the real GDP for 2015 was $\$ 16397.2$ billion dollars. Without adjustment for inflation, GDP for 1948 and 2015 were 274.8 billion dollars and 18,036.6 billion dollars respectively. Using real GDP the U.S. economy has increased its annual production of goods and services more than $811.74 \%$ from 1948. On the other hand, using GDP it would seem the U.S. economy has increased the production of goods and services by 6563.53 RGDP would grow at a constant annual average rate of 3.20 percent. This model indicates variables are statistically highly significant at $1 \%$ level of significance and it has high $\mathrm{R}^{2}$ value which is a sign of good fitted model. This high $\mathrm{R}^{2}$ represents this model explains $99.06 \%$ of the variability of the response data around its mean $\%$. The economy is growing at a constant rate because this study found an upward trend in real GDP.

Experimenting with second and third order models compared to first order model found that a second orderlinearized model is the best fits model. The $2^{\text {nd }}$ order linearized model (equation 5) shows real GDP grew by 7.6 percent in 1949 and continued to grow at a decreasing rate. This model reveals real GDP is growing but at a decreasing rate and variables are statistically significant and it has high $\mathrm{R}^{2}$ value which represents that $99.71 \%$ of the variation explained by the model. It can be shown that first order exponential model line is closely follows actual line until it reaches to 2005 period of year and after 2005 it dramatically deviated from actual line which indicated RGDP growing faster after 2005. However, second order exponential model is more closely follows the actual line throughout the period between 1948 and 2005 but after 2005 variance looks more tighter compared to first order exponential model.

The first order exponential model in figure 2 used (business cycle) to see the departure from actual data. It can be seen that during the economics expansion there was a boom but in the time of recession economy was sluggish. When economy was in boom, there was a peak and during recession a trough. In this study business cycle is counted one full peak and one full trough. The real GDP with a forecast of the next 20 years starting from 2015 to 2035, and the second order regression Y model (shown in equation 4) is used to estimate the forecast real GDP levels. The second order exponential model is kind of smooth curve that means there is no significant fluctuation in this curve. In 2015 actual and real GDP was equal to 16.397 trillion compared with estimated real GDP of 16.487 trillion. In 2016, the first year forecast, real GDP was predicted to be 17408.3 billion, and grows to 24918.2 billion by 2035 . The regression results (equation 8) indicate the average growth rate was 4.2 percent in 1949 and declines 0.03 percentage points per year but economy is growing at a decreasing rate. The second order polynomial model exhibits (equation 10) that the Real GDP grew at an average rate of 5.21 percent in 1948 and that rate is declining 0.04 percentage points each year, with an additional loss of 4.8 percentage points in a recessionary year.

Recessionary model has been used for the analysis and recessionary model reports an average growth rate in employment to be 2.9 percent that is slowing at a rate of 0.02 percentage points per year and by an additional 4.2 percentage points in the recessionary periods. The decline of the growth rate in the model is less than the decline of the growth rate in the optimistic model. The variance in the data from the trends for RGDP, labor, and capital seem to be better explained when recessionary periods taken into consideration. For the purposes of projecting growth rates of each series, an average of the optimistic and recessionary models may be calculated. Unforeseen occurrences can severely alter these projections for the better, or worse.

Cob Douglas production function has been to explaining and forecasting economic growth. This model found that a ten percent increase change in capital $(\mathrm{K})$ leads to a $1.1 \%$ percent change in production and a ten percent change in labor (L) leads to a 6.3 percent change in production. The total average growth of output over time is approximately 3.13 percent. To understand the effect of each variable in the output composition, growth accounting is utlilized. The output growth model gives an important insight into the actual effects of technology, labor, and capital. 57.5 percent of output growth depends on technology, 28.8 percent depends on labor, and 12 percent depends on capital. It can be observed that technology has the greatest impact on output and that labor outweighs capital. Since technology seems to be the most significant factor of output, it would be beneficial to model its growth.

Later economic theory used to refine the structural forecast and found that the estimated coefficient of the mode is 0.0187 , and contribution of capital growth is 0.131 percent. These coefficients can be compared to be ones obtained in the explaining economic growth section equation (16). Equation (29) has considered the better estimator of the growth rate of GDP because it works under the assumption that all firms' maximizes profit. The restricted variable for the growth of labor of 0.55 means that if labor increases by one percent then output increases in productivity. Compared with the growth rates obtained in equation (29) labor is more productive, meaning that the other inputs do not have to be as large to have as large of an effect of output.

Of course there are deviations from these models, and they can be explained by exploring business cycle data. Typically during an expansionary period of time will underperform the model. The longest business cycle the U.S. has experienced was from 1989-2008, under which the economy had its longest stretch of better than experience performance. U.S. economic growth has occurred due to increase in capital, labor and technology. A $10 \%$ increase in the growth rate of labor will result in 5.54\% increase in the growth of output. A $10 \%$ increase in capital will increase output by $1.97 \%$ and our current technology will increase growth of output by (0.022-0.00016t) where $t=$ number of years from current 
year. Currently, an increase in labor will result in the greatest increase in growth of output.

In 20 years the projected GDP ranges from $\$ 19138.8$ using the polynomial model to $\$ 34681.8$ for the first order exponential model, and moderate of $\$ 24878.7$ when using the $2^{\text {nd }}$ order exponential model. According to the first order exponential model, the growth rate of the U.S. economy should show down to a rate of $1.38 \%$ in the year 2035 from our current rate of $2.07 \%$ in 2015 . The growth rate is decreasing due to diminishing returns to labor and capital. The best way to grow an economy is to increase the level of technology. This makes labor more productive, and in the United States, this will increase the growth of output by $0.554 \%$.

\section{Conclusion}

After exploring many models, this study can come up a calculation that the U.S. economy has been on a path of growth and that rate of growth is slowing. Three influential factors of growth are less the labor force, technology, and capital. Growth of technology is the most influential, and thus special attention should be given its advancement. A key idea to take away from this paper is that while a model fit the current data well, it may weigh recent events to heavily, recessionary or exponential growth, the average between the most optimistic and pessimistic models may be the best bet. The U.S economy will most likely continue to see booms and busts, while in a boom, plan for a bust.

In 1948 the size of the U.S. economy was $\$ 2010.0$ billion and has increased to $\$ 16,379.2$ billion, both measured in 2009 dollars. As indicated by a first order exponential model, the U.S. economy is growing at $3.2 \%$ each year, but there is evidence to suggest that the growth rate has been diminishing as time has gone on. A second order exponential model shows that the growth rate was higher at $0.04 \%$, but the rate has been diminishing throughout the history of the U.S. at a rate of $0.00015 \%$ for each year. The growth rate will diminish at a faster rate during recessionary periods. This research also found that labor growth rate has been decreasing at a rate of $0.02 \%$ per year, and this is exacerbated during recessionary periods. The capital growth rate has similar fashion and it has been decreasing at a rate of $0.04 \%$ per year. US experienced the longest business cycle during the period of 1989 to 2008 . The results shows that total production was made up of $57.5 \%$ technology, $28.8 \%$ labor, and $12.8 \%$ capital which clearing indicates that technology has that greatest impact on total production and changes in labor and capital have the significantly lower affect the growth rate of the economy.

It was also discovered that the models were not completely correct in that it underestimated the impact of expansionary periods and over exaggerated the effects of recessionary periods of the US economy. It should be highlighted that from 1989-2008, the US experienced the longest business cycle where the economy showed better than expected performance for that time. Unfortunately, this period ended abruptly with the Great Recession. The use of growth accounting specified how each factor of production contributed to the economic growth, each represented as a percent. The findings were conclusive in that total production was made up of $57.5 \%$ technology, $28.8 \%$ labor, and $12.8 \%$ capital. Knowing this, it is further affirmed that technology makes up the greatest fraction of total production and changes in labor and capital would not affect the growth rate as much as technology can. By looking at the forecast models, it was projected that in 20 years, the GDP level could be anywhere from $\$ 19,138.8$ using the polynomial model to $\$ 34,681.8$ using the first order exponential model. Currently, the growth rate of GDP is at $2.07 \%$ as of 2015 , but using the first order exponential model, it will slow down to $1.38 \%$ by 2035 .

It can be concluded that the most effective way to increase the growth rate is to increase the level of technology because the diminishing returns to labor and capital decrease the growth rate of GDP. Three models were used to forecast the rate of technology. A constant technological growth model was used to forecast estimates for average labor and capital for optimistic and pessimistic predictions. Another model allowed for a varying technological growth rate and resulted in the most pessimistic forecast with a decreasing growth rate. The last model accounted for improvements in technology that was similar to work force improvements and forecasted the most conservative model of the three. Using a combination of these three models, a range can be obtained to predict what will be seen in the US economy in the next twenty years.

\section{Appendix}

$$
\begin{array}{ll}
{[1]} & \pi=R-C \\
{[2]} & \pi=P Y-[W L+R K] \\
{[3]} & \pi=P Y-W L-R K \\
{[4]} & \pi=P(A L)^{\beta} k^{\alpha}-W L-R K \\
{[5]} & \frac{d \pi}{d L}=\frac{d}{d l}=P(A L)^{\beta} K^{\alpha}-W L-R K \\
{[6]} & \frac{d \pi}{d L}=\frac{d}{d l}=\left[P(A L)^{\beta} K^{\alpha}\right]+\frac{\partial}{\partial L}[-W L]+\frac{\partial}{\partial L}[R K] \\
{[7]} & \frac{d \pi}{d L}=\frac{d}{d l}=\left[P(A L)^{\beta} K^{\alpha}\right]+\frac{\partial}{\partial L}[-W L] \\
{[8]} & \frac{d \pi}{d L}=\frac{d}{d l}=P A^{\beta} K^{\alpha}+\frac{\partial}{\partial L}\left[L^{\beta}\right]-W \frac{\partial}{\partial L}[L] \\
{[9]} & \frac{d \pi}{d L}=P A^{\beta} K^{\alpha} B L^{\beta-1}-W \\
{[10]} & P A^{\beta} K^{\alpha} B L^{\beta-1}-W=0 \\
{[11]} & P A^{\beta} K^{\alpha} B L^{\beta-1}=W \\
{[12]} & \beta P A^{\beta} L^{\beta-1} K^{\alpha}=W \\
{[13]} & \beta P A^{\beta} L^{\beta} K^{\alpha}=W \\
{[14]} & \beta P Y=W \\
{[15]} & \beta=\frac{W L}{P Y}
\end{array}
$$

\section{References}

[1] Gordon, R. (2012). Is U.S. Economis Growth over? Falterring innovation confronts. National Bureau of economic research, 1-25. 
[2] Charles, J. I. (2002). Sources of U.S. Economic Growth in a World of Ideas. American Economic Review, 220-239.

[3] Chowdhury, M. N., Uddin, M. J., \& Islam, M. S. (2014). An econometric analysis of the determinants of foreign exchnge reserve in Bangladesh.. Journal of World Economic Research, $72-82$.

[4] Corrado, C., Charles, R., \& Daniel, E. (2006). Intangible Capital and Economic Growth. Staff working papers in the Finance and Economics Discussion Series (FEDS).

[5] Corrado, C., Hulten, C., \& Sichel, D. (2009). Intangiable Capital and U.S. Economic growth. Review of Income and Weath, 55.

[6] Jorgenson, D. (1099). Productivity and Postwar U.S. Economic Growth. Journal of Economic Perspective, 2 (4), 23-41.
[7] Jorgenson, D. W., \& Fraumeni, B. (1992). Investment in Education and U.S. Economic Growth. The Scandinavian Journal of Economics, 51-70.

[8] Jorgenson, D., \& Stirion, K. (2000). Raising the Speed Limit: U.S. Economic Growth in the Information Age. Brookings Paper on Economic Activity, 2000 (1), 125-235.

[9] Jorgerson, D., Gollop, F., \& Fraumeni, B. (1991). Productivity and U.S. Economic Growth. Elsevier Science Publisher.

[10] Uddin, M., Chowdhury, N. M., \& Ahmed, M. (2015). Impact of ADP on GDP in Bangladesh: A Cointegration Approach. International Journal of Econometrics anc Financial Management, 3 (2), 44-56. 